\title{
Delineation of yet unknown cryptic subtelomere aberrations in $50 \%$ of acute myeloid leukemia with normal GTG-banding karyotype
}

\author{
MADELEINE GROSS $^{1}$, HASMIK MKRTCHYAN ${ }^{1}$, MELANIE GLASER ${ }^{1}$, HANS JÖRG FRICKE ${ }^{2}$, \\ KLAUS HÖFFKEN $^{2}$, ANITA HELLER ${ }^{1}$, ANJA WEISE ${ }^{1}$ and THOMAS LIEHR $^{1}$ \\ ${ }^{1}$ Institut für Humangenetik und Anthropologie, Kollegiengasse 10, D-07743 Jena; \\ ${ }^{2}$ Klinik fuer Innere Medizin II, Erlanger Allee 101, D-07747 Jena, Germany
}

Received August 29, 2008; Accepted November 3, 2008

DOI: 10.3892/ijo_00000165

\begin{abstract}
Acute myeloid leukemia (AML) is a heterogeneous disease with respect to clinical prognosis and acquired chromosomal aberrations. After routine banding cytogenetic analysis $45 \%$ of AML patients show a normal karyotype (NK-AML). For a better understanding of development and progression in AML, it is important to find markers which could be primary genetic aberrations. Therefore, in this study 31 patients with NK-AML were analyzed by new high resolution molecular cytogenetic approaches. A combination of multitude multicolor banding and metaphase microdissection-based comparative genomic hybridization revealed deletions of the subtelomeric regions in $6 \%$ of the studied cases. According to these results, locus-specific probes for the subtelomeric regions of chromosomes 5, 9, 11 , 12 and 13 were applied on 22 of the studied 31 NK-AML cases. Surprisingly, $50 \%$ of them showed deletions or duplications. These aberrations occurred in the in vitro proliferating as well as in the non-proliferating cells. Metaanalysis of the aberrant regions revealed that they often include genes known to be associated with tumors, e.g. RASA3 on chromosome 13. These results implicate that aberrations in the subtelomeric regions of NK-AML occur quite often and may be considered as primary genetic changes, and should not be neglected in future diagnostic approaches.
\end{abstract}

\section{Introduction}

The occurrence of acute myeloid leukemia (AML) is based on acquired genetic alterations, resulting in an accumulation of

Correspondence to: Dr Thomas Liehr, Institut für Humangenetik und Anthropologie, Postfach, D-07740 Jena, Germany

E-mail: i8lith@mti.uni-jena.de

Key words: acute myeloid leukemia, microdissection-based comparative genomic hybridization, multitude multicolor banding, subtelomere hematopoietic progenitor cells. At the time of diagnosis $~ 55 \%$ of the patients show at least one chromosomal aberration in their bone marrow blasts where $>200$ different aberrations are described until now (1). However, $45 \%$ of the patients with de novo AML still show a cytogenetic normal karyotype (NK-AML) $(2,3)$. Recent studies gave evidence that in addition to chromosomal aberrations genetic changes can occur. These include e.g. mutations in the FLT3 (4), the NPM1 $(5,6)$ or the MLL gene $(7,8)$. Also acquired isodisomy were described (9-11). The latter are regions of homozygosity of which the importance for the development of AML has not been sufficiently clarified yet.

Patients with NK-AML are classified in the intermediate prognostic group, which allows no precise prediction of the outcome or an individual therapy for each patient $(12,13)$. Besides the age of the patients, cytogenetic aberrations are important for therapy planning and prognosis. However, bone marrow chromosomes show a poor resolution and morphology and therefore banding cytogenetic analysis of such chromosomes is performed on band levels between 200-300 bands per haploid karyotype. Therefore, it is a well known problem in leukemia cytogenetics that cryptic chromosomal aberrations can easily be disregarded.

The introduction of molecular cytogenetics, especially of multicolor fluorescence in situ hybridization (FISH) leads to better results and identification of previously cryptic chromosomal aberrations in leukemia cytogenetics and furthermore make interphase nuclei accessible $(1,2)$. Compared to whole genome approaches like array-based comparative genomic hybridization (array-CGH), a further advantage of FISH is the analysis of single cells. The latter allow also the study of rare cell lines which are typically found in leukemia patients. Previous FISH studies (14-18) including metaphase comparative genomic hybridization (CGH) on NK-AML $(19,20)$ showed that these approaches are suited to pick up cryptic chromosomal rearrangements in $5-8 \%$ of the cases.

In the present study, we analyzed 31 cases with NK-AML with a new, previously not applied combination of FISH methods. We used two genome-wide FISH approaches, one interphase, i.e. microdissection-based comparative genomic hybridization (micro-CGH) (21) and one metaphase cell 

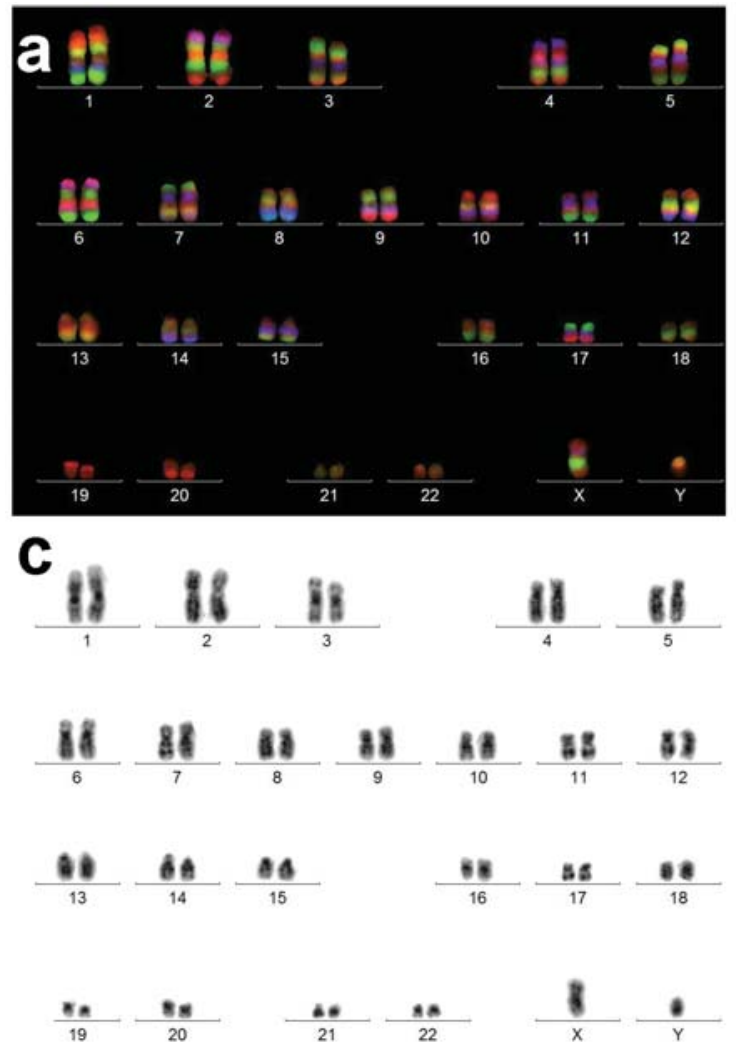

directed approach, i.e. multitude multicolor banding (mMCB) (22). Furthermore, the results were confirmed by locus-specific probes, which were used to analyze the proliferating and the non-proliferating cells of the studied cases. According to the $\mathrm{mMCB}$ and micro-CGH results, subtelomeric probe sets were subsequently applied on 22 of the 31 NK-AML cases.

\section{Materials and methods}

Patients. Thirty-one patients with de novo AML or AML derived from MDS (myelodysplastic syndromes) presenting at diagnosis a normal karyotype after banding cytogenetics, were included in the present study (for details see Table I). The age range was 27 to 78 with a median of 55 years and a male-to-female ratio of 2:4. The number of blasts varied from $10-100 \%$. According to the French-American-British Classification, cases from all AML-subtypes except AML-M7 were present.

Banding cytogenetics. Cytogenetic studies applying GTGbanding was performed according to standard protocols (23). Two hundred to 350 bands per haploid karyotype and at least 15 metaphases were analyzed per patient. As aforementioned GTG-banding revealed a karyotype of $46, \mathrm{XX}$ or $46, \mathrm{XY}$, respectively.

Fluorescence in situ hybridization (FISH). FISH was done according to standard protocols described in Liehr et al (26). The mMCB probe set was used as published in (22). These probes were further specified later (24). Microdissectionbased comparative genomic hybridization (micro-CGH) (21)

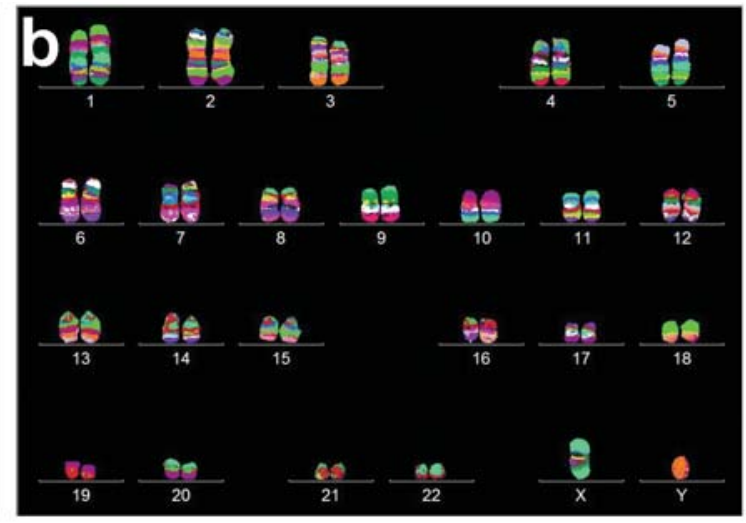

Figure 1. mMCB result of case 28. In (a) the staining of the chromosomes in three of the five fluorochromomes (TexasRed, cyanine 5 and diethylaminocoumarine) and (b) the results are depicted in pseudo-colors (ISIS, Metasystems, Altlussheim, Germany). (c) Inverted DAPI banding of the same karyogram. In this case no aberrations were detected by $\mathrm{mMCB}$.

was performed according to the modifications, as previously described (25). For mMCB and for micro-CGH 15-20 metaphases were evaluated.

Locus-specific DNA probes from the subtelomeric region of chromosomes 5, 9, 11, 12 and 13 were purchased as BAC clones from the Children's Hospital Oakland Research Institute (CHORI), Oakland, CA, USA. Plasmid DNA from BAC clones was isolated, amplified and labeled by PCR and subsequently used for FISH, as described (26). In order to have a probe set that is also reliable in interphase FISH at least three BAC clones from the same chromosomal region were combined to a probe-set and labeled in the same color (Table II). For chromosome 5 only one BAC clone from the subtelomeric region was available. For each FISH probe 15-20 metaphases and 150 interphase nuclei were analyzed. The cut-off level for the analyses of interphase nuclei was determined as $5 \%$.

Meta-analysis. The regions identified to be deleted in the aforementioned FISH-experiments were analyzed for their genetic content using database of NCBI (36.2) (http://www. ncbi.nlm.nih.gov) and database of genetic and cytogenetic in haematology and oncology (http://atlasgeneticsoncology. org//index.html).

\section{Results}

Micro-CGH. In 17 of 31 NK-AML cases, sufficient amount of suspension for analysis with micro-CGH was available. In two cases gain of copy numbers for chromosome 19 and in another case loss of copy number for parts of chromosome 17 and whole chromosome 19 were observed. Application of further 


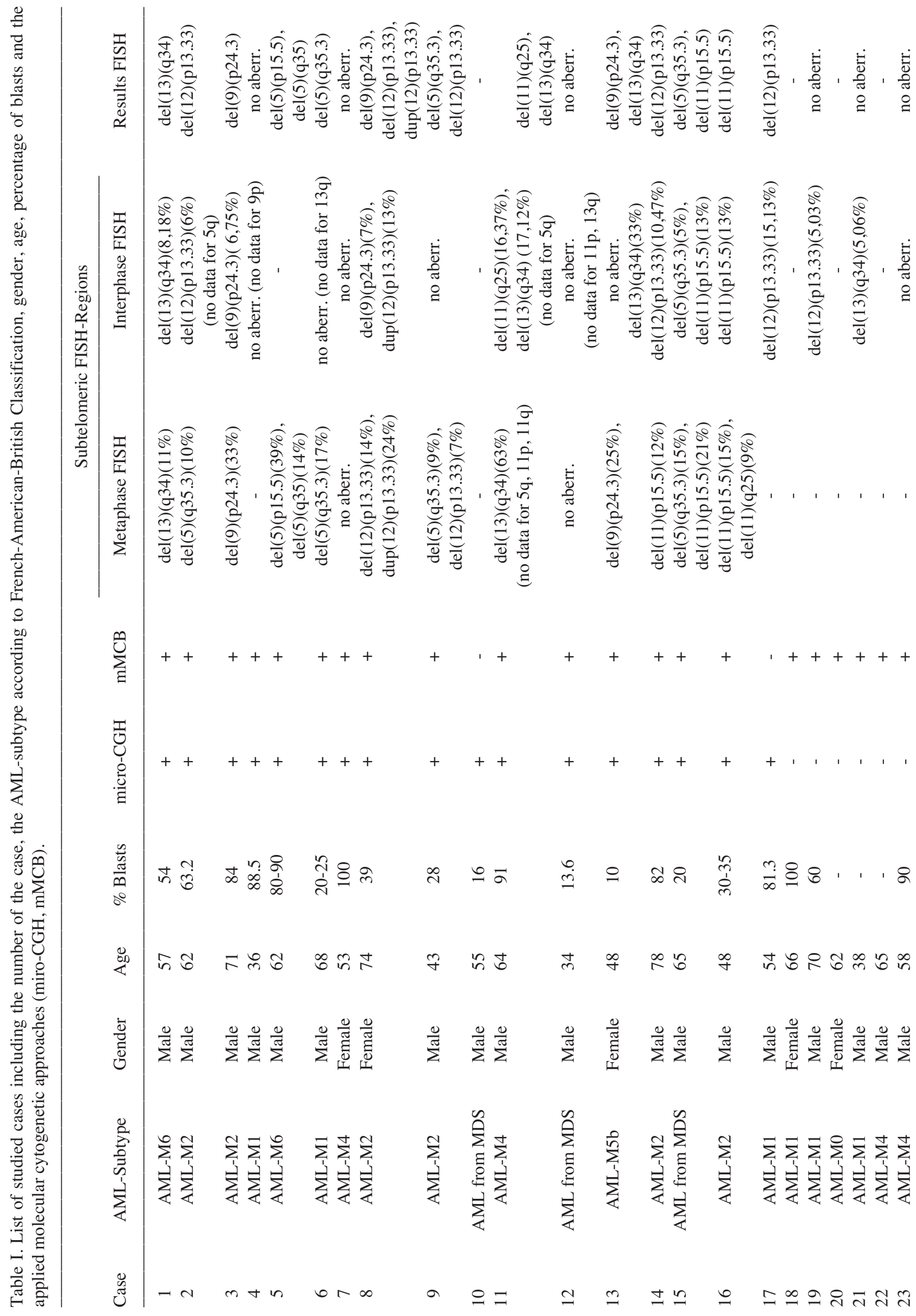




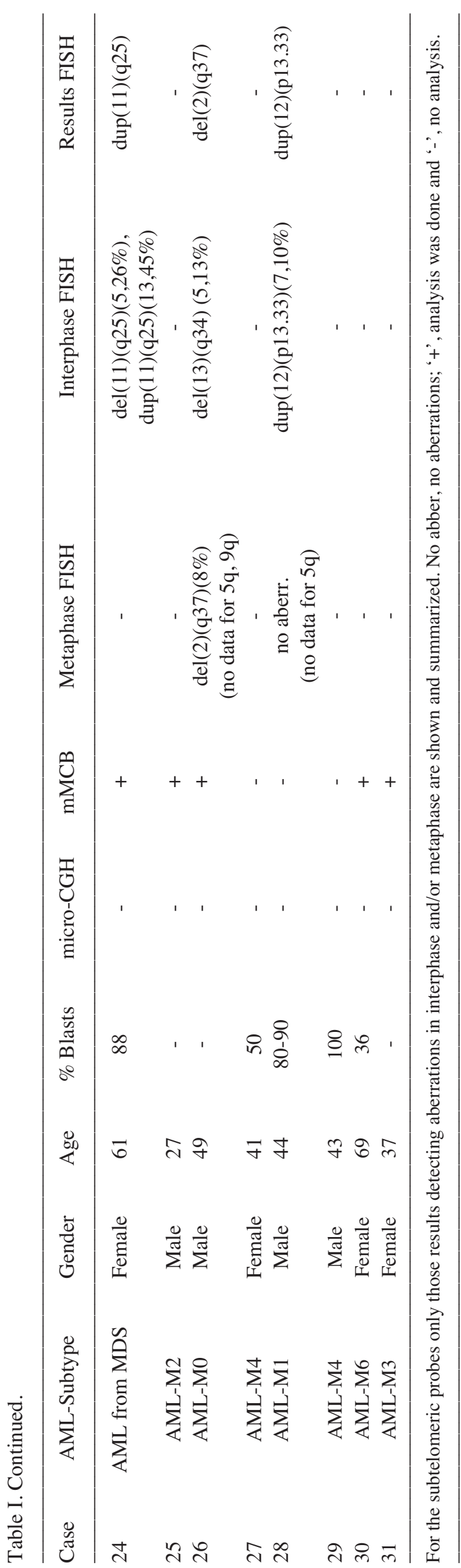

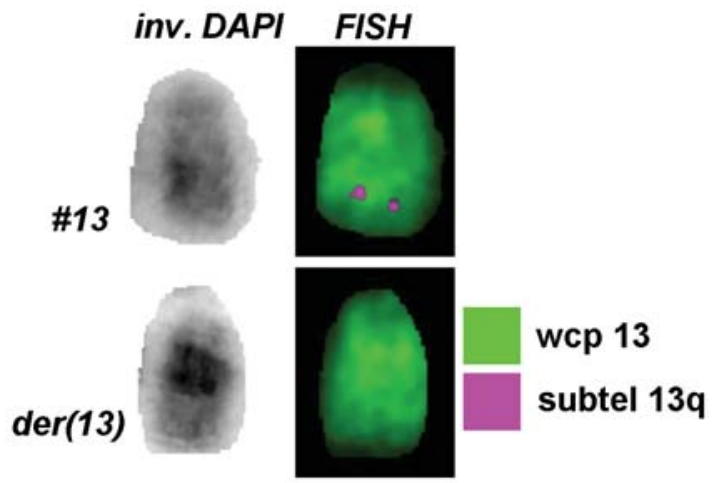

Figure 2. Hybridization result of a subtelomeric probe contigue (subtel 13q) with a whole chromosome paint for chromosome 13 (wcp 13) in case 11. The BAC contigue were labeled in TexasRed (TR), the wcp probe in Spectrum Green (SG). Due to the deletion the signal of the BAC clones is visible only on one of the homologue chromosomes. On the left hand of the FISH figures the inverted DAPI-banding (inv. DAPI) result is shown.

FISH probes (mMCB and subtelomere 19 specific probes) could not confirm these results. Thus, micro-CGH did not pick up any aberrations in the 17 studied cases.

$m M C B$. Metaphases suited for analysis by $\mathrm{mMCB}$ were obtained in 26 of 31 NK-AML cases. The mMCB probe-set revealed aberrations in 2 of the 26 studied cases which were confirmed by additional FISH probes. In case 5, three different cell clones were detectable: $46, \mathrm{XY}, \operatorname{del}(5)(\mathrm{p} 15.5)[11] / 46, \mathrm{XY}$, $\operatorname{del}(5)(\mathrm{q} 35)[4] / 46, X Y[13]$. In case 26 , a deletion in the subtelomeric region in $2 \mathrm{q}$ could be described. This deletion occurred in $8 \%$ of the metaphases. In the remaining analyzed NK-AML cases no aberrations were detectable by $\mathrm{mMCB}$ (Fig. 1).

Subtelomeric regions. In 22 of 31 cases, sufficient amount of suspension was available for the analysis of subtelomeric regions by interphase and metaphase FISH. In $50 \%$ of the analyzed 22 NK-AML cases aberrations in the subtelomeric regions were detectable, including deletions and duplications of the appropriate regions (Table I). For each case the number of detected cell clones varied from one to three. The aberrations were found in the proliferating cells, in the nonproliferating cells or in both cell types. Fig. 2 shows a deletion on chromosome 13 detected in case number 11 .

\section{Discussion}

In the present study, $17 \mathrm{NK}-\mathrm{AML}$ cases were analyzed by micro-CGH and no aberrations could be described. These results are comparable to others using metaphase-based CGH for analyzing NK-AML $(19-20,27)$. However, as already described (25) micro-CGH enables the direct analysis of tumor cells which is more informative than conventional metaphase-based CGH. Thus, no major copy number changes can be expected in NK-AML detectable by metaphase CGH. The false-positive/false negative copy number changes affected especially chromosome 19 - a region known to be not reliably informative in CGH-studies $(25,28)$. 
Table II. BAC clones from the subtelomeric regions of the chromosomes 5, 9, 11, 12 and 13 used for interphase and metaphase FISH, based on NCBI build 36.2.

\begin{tabular}{|c|c|c|c|c|c|}
\hline Chromosome & Band & BAC clone & Accession code & Start kb & End $\mathrm{kb}$ \\
\hline 5 & $\mathrm{q} 35.3$ & RP11-240G13 & - & 180.512 & 180.626 \\
\hline 9 & p34.3 & RP11-393D13 & BH141105.1 & 236 & 427 \\
\hline 9 & p34.3 & RP11-1021N5 & AQ593522.1 & 150 & 333 \\
\hline 9 & p34.3 & $2241 \mathrm{C} 11$ (Cosmid) & - & - & - \\
\hline 11 & $\mathrm{p} 15.5$ & RP11-1021K7 & AQ697676.1 & 668 & 668 \\
\hline 11 & p15.5 & RP11-51L17 & AQ052363.1 & 764 & 942 \\
\hline 11 & p15.5 & RP11-496F2 & AZ695077 & 668 & 872 \\
\hline 11 & p15.5 & 2209A2 (Cosmid) & - & - & - \\
\hline 11 & $\mathrm{q} 25$ & RP11-186N3 & AQ422456.1 & 134.184 & 134.356 \\
\hline 11 & $\mathrm{q} 25$ & RP11-1077G24 & AQ744064.1 & 133.998 & 134.194 \\
\hline 11 & $\mathrm{q} 25$ & RP11-265F9 & AQ484019.1 & 134.272 & 134.411 \\
\hline 11 & $\mathrm{q} 25$ & RP11-267D5 & AQ487857.1 & 133.964 & 134.130 \\
\hline 12 & p13.3 & RP11-519B13 & AZ916624.1 & 28 & 214 \\
\hline 12 & $\mathrm{p} 13.3$ & RP11-12H17 & B75812.1 & 345 & 484 \\
\hline 12 & p13.3 & RP11-367L11 & AQ529919.1 & 366 & 537 \\
\hline 13 & q34 & RP11-63L17 & AQ200393.1 & 113.782 & 113.954 \\
\hline 13 & q34 & RP11-960N24 & AQ739689.1 & 113.904 & 114.103 \\
\hline 13 & q34 & RP11-450H16 & AZ773446.1 & 113.958 & 114.117 \\
\hline
\end{tabular}

BAC, bacterial artificial chromosome; Band, chromosomal subband; kb, kilobasepairs and '-', not available.

The application of mMCB could identify deletions in $6 \%$ of the $31 \mathrm{NK}-\mathrm{AML}$ cases. The proof of principle for $\mathrm{mMCB}$ to detect cryptic aberrations was done on cases with MDS (22) and acute lymphoblastic leukemia (29). The FISH method mMCB is also useful to analyze mixtures of cells such as in AML cases where the studied cells comprise healthy and leukemic cells (unpublished data). In previous multicolor FISH studies whole chromosome paints as probes were applied on NK-AML cases (14-18). Surprisingly, the results from the present study are similar to those in the published studies, even though the FISH-banding approach (for review see ref. 30) mMCB allows the detection of aberrations which are not detectable by other cytogenetic methods. This means, that in NK-AML intrachromosomal changes are sparse.

A limitation of all multicolor FISH approaches using whole or partial chromosome paints as well as for CGH is that they do not provide reliable information on changes within the subtelomeric regions of the chromosomes. Therefore, in the present study locus-specific probes for the subtelomeric regions were applied. The analyzed regions were chosen according to chromosomes which are often involved in aberrations in AML (http://atlasgeneticsoncology. org//index.html). Cryptic aberrations in $50 \%$ of the $22 \mathrm{NK}-$ AML cases were found. These aberrations included deletions and duplications and occurred in the in vitro proliferating as well as the non-proliferating cells. The size of the deleted regions was at least 200 to $600 \mathrm{~kb}$ according to the $\mathrm{BAC}$ clones used for FISH. Database analysis of these regions showed that they include genes known to be associated with tumors. The deleted region on chromosome 13 has a size of at least $300 \mathrm{~kb}$ and contains the RASA3 gene. The product of this gene is a GTPase activating protein which stimulates the GTPase activity of RAS p21 (31). It is further known that $R A S$ genes have a function as proto-oncogenes and are involved in a variety of tumors $(32,33)$. The deleted regions are, excluding those on chromosomes 5 and 9 , regions that contain published copy number variations $(34,35)$. For the chromosomes 9 and 11 segmental duplications of the corresponding regions are reported, which are in general known to be predisposed for non-allelic homologues recombination (36). The deleted region on chromosome 12 is known to be often involved in rearrangements in AML (29,37-39). Our data have shown a correlation between deletion 12p and AML-subtype M2 which was also described before $(40,41)$. The remaining aberrations occurred independently from the AML-subtype, age or percentage of blasts. Furthermore, aberrations were observed in the proliferating as well as in the non-proliferating cells with no correlation to the aberration.

In conclusion, this is the first study using genome-wide FISH methods as well as locus-specific FISH probes to detect aberrations in NK-AML. In $~ 50 \%$ of the cases submicroscopic deletions could be described. These deletions might be primary genetic aberrations which lead to the development of AML. Further studies should clarify the prognostic impact of these aberrations.

\section{Acknowledgements}

Supported in parts by the Ernst-Abbe-Stiftung, IZKF Jena (Start-up S16), DFG (436 ARM 17/5/06), IZKF together with 
the TMWFK (TP 3.7 and B307-04004), Stiftung Leukämie, Stefan-Morsch-Stiftung and DAAD (D/07/09624).

\section{References}

1. Mrózek K, Heinonen K and Bloomfield CD: Clinical importance of cytogenetics in acute myeloid leukaemia. Best Pract Res Clin Haematol 14: 19-47, 2001.

2. Mrózek K, Heerema NA and Bloomfield CD: Cytogenetics in acute leukaemia. Blood Rev 18: 115-136, 2004.

3. Bacher U, Haferlach T, Schoch C, Kern W and Schnittger S: Implications of NRAS mutations in AML: a study of 2502 patients. Blood 107: 3847-3853, 2006

4. Schnittger S, Schoch C and Dugas M: Analysis of FLT3 length mutations in 1003 patients with acute myeloid leukaemia: correlation to cytogenetics, FAB subtype, and prognosis in the AMLCG study and usefulness as a marker for the detection of minimal residual disease. Blood 100: 59-66, 2002.

5. Boissel N, Renneville A, Biggio V, Philippe N, Thomas X, Cayuela JM, Terre C, Tigaud I, Castaigne S, Raffoux E, De Botton S, Fenaux P, Dombret $\mathrm{H}$ and Preudhomme C: Prevalence, clinical profile, and prognosis of NPM mutations in AML with normal karyotype. Blood 106: 3618-3620, 2005.

6. Döhner K, Schlenk RF, Habdank M, Scholl C, Rücker FG, Corbacioglu A, Bullinger L, Fröhling S and Döhner H: Mutant nucleophosmin (NPM1) predicts favorable prognosis in younger adults with acute myeloid leukemia and normal cytogenetics: interaction with other gene mutations. Blood 106: 3740-3746, 2005.

7. Döhner K, Tobis K, Ulrich R, Fröhling S, Benner A, Schlenk RF and Döhner H: Prognostic significance of partial tandem duplications of the MLL gene in adult patients 16 to 60 years old with acute myeloid leukemia and normal cytogenetics: a study of the Acute Myeloid Leukemia Study Group Ulm. J Clin Oncol 20: 3254-3261, 2002.

8. Shiah HS, Kuo YY, Tang JL, Huang SY, Yao M, Tsaw W, Chen YC, Wang CH, Shen MC, Lin DT, Lin KH and Tien HF: Clinical and biological implications of partial tandem duplication of the MLL gene in acute myeloid leukemia without chromosomal abnormalities at 11q23. Leukemia 16: 196-202, 2002.

9. Fitzgibbon J, Smith LL, Raghavan M, Smith ML, Debernardi S, Skoulakis S, Lillington D, Lister TA and Young BD: Association between acquired uniparental disomy and homozygous gene mutation in acute myeloid leukemias. Cancer Res 65: 9152-9154, 2005.

10. Raghavan M, Lillington DM, Skoulakis S, Debernardi S, Chaplin T, Foot NJ, Lister TA and Young BD: Genome-wide single nucleotide polymorphism analysis reveals frequent partial uniparental disomy due to somatic recombination in acute myeloid leukemias. Cancer Res 65: 375-378, 2005.

11. Gorletta TA, Gasparini P, D'Elios MM, Trubia M, Pelicci PG and Di Fiore PP: Frequent loss of heterozygosity without loss of genetic material in acute myeloid leukemia with a normal karyotype. Genes Chromosomes Cancer 44: 334-337, 2005.

12. Grimwade D, Walker H, Oliver F, Wheatley K, Harrison C, Harrison G, Rees J, Hann I, Stevens R, Burnett A and Goldstone A: The importance of diagnostic cytogenetics on outcome in AML: analysis of 1612 patients entered into the MRC AML 10 trial. Blood 92: 2322-2333, 1998.

13. Byrd JC, Mrózek K, Dodge RK, Carroll AJ, Edwards CG, Arthur DC, Pettenati MJ, Patil SR, Rao KW, Watson MS, Koduru PRK, Moore JO, Stone RM, Mayer RJ, Feldman EJ, Davey FR, Schiffer CA, Larson RA and Bloomfield CD: Pretreatment cytogenetic abnormalities are predictive of induction success, cumulative incidence of relapse, and overall survival in adult patients with de novo acute myeloid leukemia: results from Cancer and Leukemia Group B (CALGB 8461). Blood 100: 4325-4336, 2002.

14. Zhang FF, Murata-Collins JL, Gaytan P, Forman SJ, Kopecky KJ, Willman CL, Appelbaum FR and Slovak ML: Twenty-four-color spectral karyotyping reveals chromosome aberrations in cytogenetically normal acute myeloid leukemia. Genes Chromosomes Cancer 28: 318-328, 2000.

15. Mohr B, Bornhäuser M, Thiede C, Schäkel U, Schaich M, Illmer T, Pascheberg U and Ehninger G: Comparison of spectral karyotyping and conventional cytogenetics in 39 patients with acute myeloid leukemia and myelodysplastic syndrome. Leukemia 6: 1031-1038, 2000.
16. Cuneo A, Bigoni R, Cavazzini F, Bardi A, Roberti MG, Agostini P, Tammiso E, Ciccone N, Mancini M, Nanni M, De Cuia R, Divona M, La Starza R, Crescenzi B, Testoni N, Rege CG, Mecucci C, Lo CF, Saglio G and Castoldi G: Incidence and significance of cryptic chromosome aberrations detected by fluorescence in situ hybridization in acute myeloid leukemia with normal karyotype. Leukemia 16: 1745-1751, 2002.

17. Fröhling S, Skelin S, Liebisch C, Scholl C, Schlenk RF, Döhner H and Döhner K: Comparison of cytogenetic and molecular cytogenetic detection of chromosome abnormalities in 240 consecutive adult patients with acute myeloid leukemia. J Clin Oncol 20: 2480-2485, 2002.

18. Fröhling S, Kayser S, Mayer C, Miller S, Wieland C, Skelin S, Schlenk RF, Döhner H and Döhner K: Diagnostic value of fluorescence in situ hybridization for the detection of genomic aberrations in older patients with acute myeloid leukemia. Haematologica 90: 194-199, 2005.

19. Dalley CD, Neat MJ, Foot NJ, Burridge M, Byrne L, Amess JA, Rohatiner AZ, Lister A, Young BD and Lillington DM: Comparative genomic hybridization and multiplex-fluorescence in situ hybridization: an appraisal in elderly patients with acute myelogenous leukemia. Hematol J 3: 290-298, 2002.

20. Casas S, Aventin A, Fuentes F, Vallespi T, Granada I, Carrió A, Angel Martinez-Climent J, Solé F, Teixidó M, Bernués M, Duarte J, Maria Hernández J, Brunet S, Dolors Coll M and Sierra J: Genetic diagnosis by comparative genomic hybridization in adult de novo acute myelocytic leukemia. Cancer Genet Cytogenet 153: 16-25, 2004.

21. Heller A, Chudoba I, Bleck C, Senger G, Claussen U and Liehr T: Microdissection based comparative genomic hybridization analysis (micro-CGH) of secondary acute myelogenous leukemias. Int J Oncol 16: 461-468, 2000.

22. Weise A, Heller A, Starke H, Mrasek K, Kuechler A, Pool-Zobel BL, Claussen U and Liehr T: Multitude multicolor chromosome banding (mMCB) - a comprehensive one-step multicolor FISH banding method. Cytogenet Genome Res 103: 34-39, 2003

23. Verma RS and Babu A: Human chromosomes: Principles and techniques. 2nd edition, McGraw Hill, Inc., 1994.

24. Weise A, Mrasek K, Fickelscher I, Claussen U, Cheung SW, Cai WW, Liehr T and Kosyakova N: Molecular definition of high-resolution multicolor banding probes: first within the human DNA sequence anchored FISH banding probe set. J Histochem Cytochem 56: 487-493, 2008.

25. Karst C, Heller A, Claussen U, Gebhart E and Liehr T: Detection of cryptic aberratins in the in vitro non proliferating cells of acute myeloid leukemia. Int J Oncol 27: 355-359, 2005.

26. Liehr T, Heller A, Starke H, Rubtsov N, Trifonov V, Mrasek K, Weise A, Kuechler A and Claussen U: Microdissection based high resolution multicolor banding for all 24 human chromosomes. Int J Mol Med 9: 335-339, 2002.

27. Suela J, Alvarez S and Cigudosa JC: DNA profiling by arrayCGH in acute myeloid leukemia and myelodysplastic syndromes. Cytogenet Genome Res 118: 304-309, 2007.

28. Bayerlein K, Rith T, Verdorfer I, Liehr T, Wolff E, Girod S and Gebhart E: I-FISH control of CGH-detected gain of DNA sequence copy number in oral squamous cell carcinomas (OSCC). Anticancer Res 20: 427-432, 2000.

29. Karst C, Gross M, Haase D, Wedding U, Höffken K, Liehr T and Mkrtchyan H: Novel cryptic chromosomal rearrangements detected in acute lymphoblastic leukemia detected by application of new multicolor fluorescent in situ hybridization approaches. Int J Oncol 28: 891-897, 2006.

30. Liehr T, Starke H, Heller A, Kosyakova N, Mrasek K, Gross M, Karst C, Steinhaeuser U, Hunstig F, Fickelscher I, Kuechler A, Trifonov V, Romanenko SA and Weise A: Multicolor fluorescence in situ hybridization (FISH) applied to FISHbanding. Cytogenet Genome Res 114: 240-244, 2006.

31. Bottomley JR, Reynolds JS, Lockyer PJ and Cullen PJ: Structural and functional analysis of the putative inositol 1,3,4,5tetrakisphosphate receptors GAP1 (IP4BP) and GAP1 (m). Biochem Biophys Res Commun 250: 143-149, 1998.

32. Barbacid M: Ras genes. Ann Rev Biochem 56: 779-827, 1987.

33. Bos JL: Ras oncogenes in human cancer: a review. Cancer Res 49: 4682-4689, 1989

34. Iafrate AJ, Feuk L, Rivera MN, Listewnik ML, Donahoe PK, Qi Y, Scherer SW and Lee C: Detection of large-scale variation in the human genome. Nat Genet 36: 949-951, 2004. 
35. Sebat J, Lakshmi B, Troge J, Alexander J, Young J, Lundin P, Maner S, Massa H, Walker M, Chi M, Navin N, Lucito R, Healy J, Hicks J, Ye K, Reiner A, Gilliam TC, Trask B, Patterson N, Zetterberg A and Wigler M: Large-scale copy number polymorphism in the human genome. Science 305 : 525-528, 2004.

36. Sharp AJ, Locke DP, McGrath SD, Cheng Z, Bailey JA, Vallente RU, Pertz LM, Clark RA, Schwartz S, Segraves R, Oseroff VV, Albertson DG, Pinkel D and Eichler EE: Segmental duplications and Copy-Number Variation in the Human Genome. Am J Hum Genet 77: 78-88, 2005.

37. Andreasson P, Johansson B, Billström R, Garwicz S, Mitelman F and Höglund M: Fluorescence in situ hybridization analyses of hematologic malignancies reveal frequent cytogenetically unrecognized 12p rearrangements. Leukemia 12: 390-400, 1998.

38. O'Connor HE, Butler TA, Clark R, Swanton S, Harrison CJ, Secker-Walker LM and Foroni L: Abnormalities of the ETV6 gene occur in the majority of patients with aberrations of the short arm of chromosome 12: a combined PCR and Southern blotting analysis. Leukemia 12: 1099-1106, 1998.
39. Hagihara M, Kobayashi H, Miyachi $\mathrm{H}$ and Ogawa T: Clinical heterogeneity in acute myelogenous leukemia with the $8 ; 21$ translocation. Keio J Med 40: 90-93, 1991.

40. Klaus M, Haferlach T, Schnittger S, Kern W, Hiddemann W and Schoch C: Cytogenetic profile in de novo acute myeloid leukemia with FAB subtypes M0, M1 and M2: a study based on 652 cases analyzed with morphology, cytogenetics, and fluorescence in situ hybridization. Cancer Genet Cytogenet 155: 47-56, 2004.

41. Tyybäkinoja A, Vilpo J and Knuutila S: High resolution oligonucleotide array-CGH pinpoints genes involved in cryptic losses in chronic lymphocytic leukemia. Cytogenet Genome Res 118: 8-12, 2007. 